\title{
Nerve Terminal Currents Induced by Autoreception of Acetylcholine Release
}

\author{
Wen-Mei Fu, Houng-Chi Liou, and Yu-Hwa Chen \\ Pharmacological Institute, College of Medicine, National Taiwan University, Taipei, Taiwan 100
}

The activation of autoreceptors is known to be important in the modulation of presynaptic transmitter secretion in peripheral and central neurons. Using whole-cell recordings made from the free growth cone of myocyte-contact motoneurons of $\mathrm{Xe}$ nopus cell cultures, we have observed spontaneous nerve terminal currents (NTCs). These spontaneous NTCs are blocked by d-tubocurarine (d-TC) and $\alpha$-bungarotoxin $(\alpha-$ BuTx), indicating that endogenously released acetylcholine (ACh) can produce substantial membrane depolarization in the nerve terminals. Local application of NMDA to the growth cone increased the frequency of spontaneous NTCs. When the electrical stimulations were applied at the soma to initiate evokedrelease of $\mathrm{ACh}$, evoked $\mathrm{ACh}$-induced potentials were recorded in the nerve terminals, which were inhibited by d-TC and hexamethonium but not by atropine. Replacement of normal Ringer's solution with high- $\mathrm{Mg}^{2+}$, low- $\mathrm{Ca}^{2+}$ solution also reversibly inhibited evoked ACh-induced potentials. The possible regula- tory role of presynaptic nicotinic autoreceptors on the synaptic transmission was also examined. When the innervated myocyte was whole-cell voltage-clamped to record synaptic currents, application of hexamethonium inhibited the amplitude of evoked synaptic currents at a higher degree than that of iontophoretic ACh-induced currents. Furthermore, hexamethonium markedly reduced the frequency of spontaneous synaptic currents at high-activity synapses. Pretreatment of neurons with $\alpha$-BuTx also inhibited the evoked synaptic currents in manipulated synapses. These results suggest that $A C h$ released spontaneously or by electrical stimulation may act on the presynaptic nicotinic autoreceptors of the same nerve terminals to produce membrane potential change and to regulate synaptic transmission.

Key words: autoreceptor; neuronal nicotinic receptor; Xenopus laevis; nerve terminal currents; synaptic transmission; acetylcholine
The activation of autoreceptors is known to be important in the modulation of presynaptic transmitter secretion in the peripheral nervous system and CNS. Presynaptic inhibitory $5-\mathrm{HT}_{1}$ autoreceptors have been identified in virtually all parts of the CNS (Gothert et al., 1996). Dopaminergic, noradrenergic, and glutamatergic neurons are also inhibited by the activation of presynaptic $\mathrm{D}_{2}$-like, $\alpha_{2}$, and metabotropic glutamate autoreceptors, respectively (Boehm and Huck, 1996; Macek et al., 1996; Cragg and Greenfield, 1997). The activation of $\mathrm{GABA}_{\mathrm{B}}$ autoreceptors is indeed capable of reducing GABA release (Misgeld et al., 1995).

Nicotinic receptors are widely distributed in the mammalian CNS and have been implicated in various physiological and pathological conditions, including cognition, Alzheimer's disease, Parkinson's disease, anxiety, and addiction to tobacco products (Nordberg et al., 1989; Arneric et al., 1995). Nicotinic receptors are localized on both presynaptic axon terminals and postsynaptic somatodendritic sites (Clarke, 1993; Sargent, 1993). Most of the functions of postsynaptic receptors involved in cholinergic mediation in the CNS have not been well established. However, the positive modulation of neurotransmitter release appears to be a widespread and potentially important role of presynaptic nicotinic ACh receptor channels (nAChRs) (McGehee and Role, 1995; McGehee et al., 1995). Presynaptic nAChRs are known to positively modulate the release of various neurotransmitters, including glutamate, norepinephrine, 5-hydroxytryptamine, dopa-

Received June 29, 1998; revised Sept. 14, 1998; accepted Sept. 22, 1998.

This work was supported by a grant from the National Science Council. We thank I. S. Peng for help in the preparation of this manuscript.

Correspondence should be addressed to Dr. Fu at the above address.

Copyright (ㄷ) 1998 Society for Neuroscience $\quad 0270-6474 / 98 / 189954-08 \$ 05.00 / 0$ mine, and GABA (Wonnacott et al., 1989; Levin, 1992; Wessler, 1992; Guo et al., 1998; Li et al., 1998). As for ACh release, although an abundant literature describes the inhibitory presynaptic autoreceptors of the muscarinic type (Starke et al., 1989), nicotinic autoreceptors have been proposed also to regulate ACh release at motor nerve terminals (Bowman et al., 1988) and in central cortical and hippocampal synaptosomes (Rowell and Winkler, 1984; Araujo et al., 1988; Wilkie et al., 1996). Nicotinic autoreceptors may constitute a potential therapeutic target for enhancing cholinergic transmission in the earlier stages of diseases, such as Alzheimer's disease. The concept of ionotropic autoreceptors is established primarily by indirect evidence measuring the overflow of radioisotope-labeled transmitter or wholecell recording of EPSC amplitude at postsynaptic cells. Recently, direct recording of nicotinic responses in presynaptic nerve terminals has been made in ciliary ganglia (Coggan et al., 1997). Furthermore, measurements of intracellular $\mathrm{Ca}^{2+}$ in single mossy fiber presynaptic terminals indicate that nAChRs containing the $\alpha 7$ subunit can mediate a $\mathrm{Ca}^{2+}$ influx that is sufficient to induce vesicular neurotransmitter release (Gray et al., 1996). Here, we made whole-cell recordings from the nerve growth cone and observed spontaneous nerve terminal currents (NTCs), indicating that the activation of ionotropic autoreceptors by endogenously released $\mathrm{ACh}$ can produce the change in membrane potential.

\section{MATERIALS AND METHODS}

Cell culture. Culture procedures have been described previously (Tabti and Poo, 1991). Briefly, neural tubes and the associated myotomal tissue were taken from stage 20-22 Xenopus embryos (Nieuwkoop and Faber, 1967) and allowed to dissociate in $\mathrm{Ca}^{2+}$ - and $\mathrm{Mg}^{2+}$-free Ringer's solu- 
tion supplemented with EDTA. The dissociated cells were plated on clean coverslips and used for experiments after incubation in culture medium for $1 \mathrm{~d}$ at room temperature $\left(20-22^{\circ} \mathrm{C}\right)$. The culture medium consisted of $50 \%$ (v/v) Ringer's solution ( $115 \mathrm{~mm} \mathrm{NaCl}, 2 \mathrm{mM} \mathrm{CaCl}_{2}, 1.5$ $\mathrm{mm} \mathrm{KCl}$, and $10 \mathrm{~mm}$ HEPES, $\mathrm{pH} 7.6$ ), 49\% L-15 Leibovitz medium (Sigma, St. Louis, MO), $1 \%$ fetal bovine serum (Life Technologies, Gaithersburg, MD), and antibiotics $(100 \mathrm{U} / \mathrm{ml}$ penicillin and $100 \mu \mathrm{g} / \mathrm{ml}$ streptomycin).

Electrophysiology. Whole-cell patch-clamp recording methods followed those described previously (Hamill et al., 1981). NTCs were recorded from growth cone by whole-cell recording [holding potential $\left(\mathrm{V}_{\mathrm{h}}\right)=-60$ $\mathrm{mV}]$ in Ringer's solution by using 1-d-old cell cultures at room temperature. Patch pipettes were pulled with a two-stage electrode puller (pp-83; Narishige, Tokyo, Japan), and the tips were polished immediately before the experiment with use of a microforge (MF-83; Narishige). The solution inside the recording pipette contained $150 \mathrm{~mm} \mathrm{~K}$ gluconate, 1

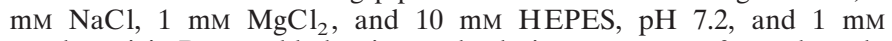
amphotericin $\mathrm{B}$ was added to internal solution to get a perforated patch. The membrane currents were monitored by a patch-clamp amplifier (Axopatch 200A, Axon Instruments, Foster City, CA) and chart recordings from an oscillographic recorder (Gould RS 3200, Valley View, OH). Data were stored on a videotape recorder for later playback onto a storage oscilloscope (5113; Tektronix) and for analysis by a microcomputer. Spontaneous synaptic currents (SSCs) were monitored from innervated myocyte by whole-cell voltage-clamp recordings $\left(\mathrm{V}_{\mathrm{h}}=-60\right.$

\section{$a$}

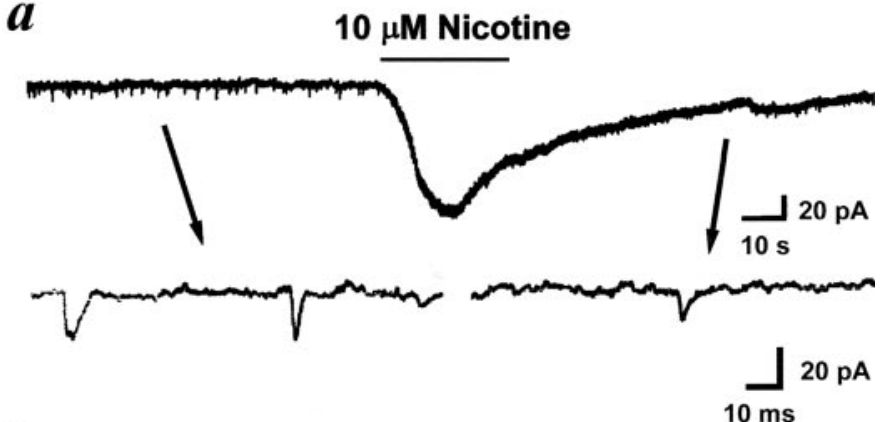

b

\section{$40 \mu \mathrm{M} d-T C$}

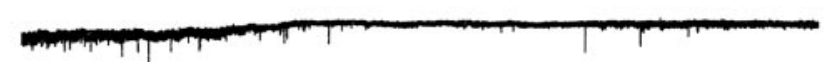

$\underset{10 \mathrm{~s}}{\perp 20}$

$\boldsymbol{C}$

c $40 \mu \mathrm{M}$ d-TC

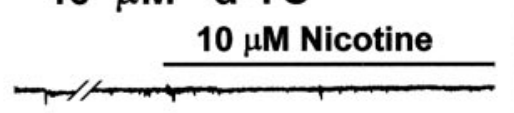

$d$
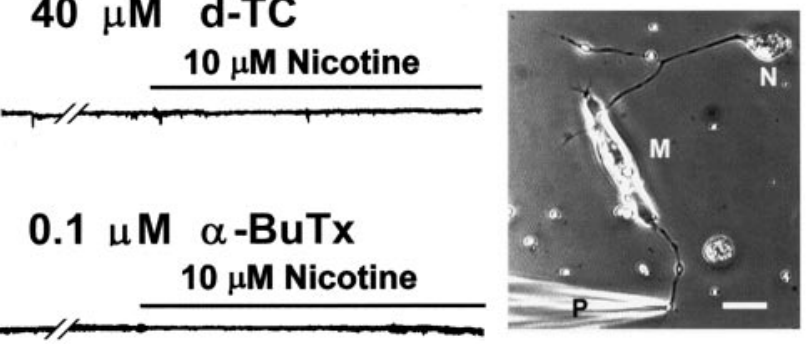

Figure 1. Spontaneous nerve terminal currents induced by the quantal release of ACh from the same nerve growth cone in 1-d-old Xenopus cultures. Phase-contrast micrograph in the bottom right corner shows the myocyte-contact neuron and the arrangement of the patch pipette for the whole-cell recording of nerve growth cone. Scale bar, $20 \mu \mathrm{m}$. $N$, Neuron; $M$, myocyte; $P$, patch pipette. $a$, Continuous trace depicts the membrane currents recorded from the nerve growth cone before and after local application of nicotine. Downward deflections are spontaneous NTCs $\left(\mathrm{V}_{\mathrm{h}}\right.$ $=-60 \mathrm{mV}$, filtered at $150 \mathrm{~Hz}$ ). Local perfusion with nicotine induced an inward current and reduced the frequency of NTCs. Samples of NTCs before and after nicotine treatment are shown below at higher time resolution (filtered at $10 \mathrm{kHz}$ ). $b$, Application of d-TC inhibited the frequency of NTCs. Pretreatment of culture with d-TC $(c)$ or $\alpha$-BuTx $(d)$ inhibited the appearance of NTCs and completely antagonized the nicotine-induced inward current. $\boldsymbol{a}$ $100 \mu \mathrm{M}$ NMDA

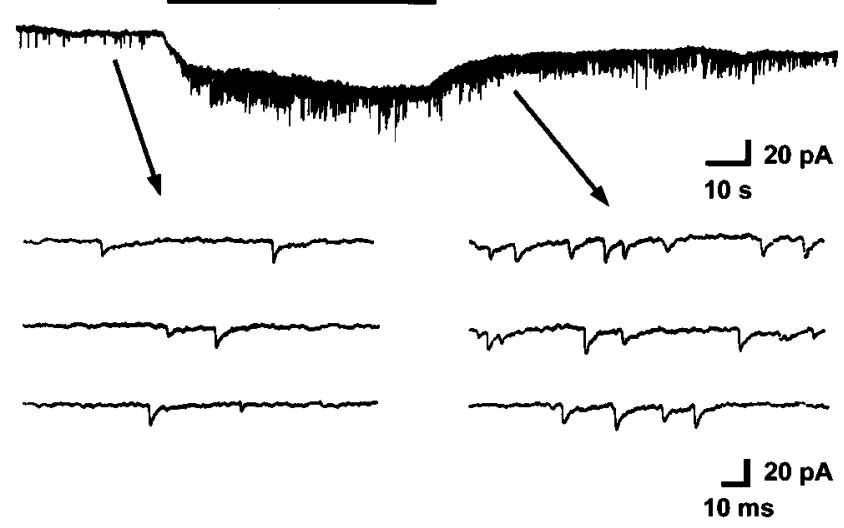

$\boldsymbol{b}$

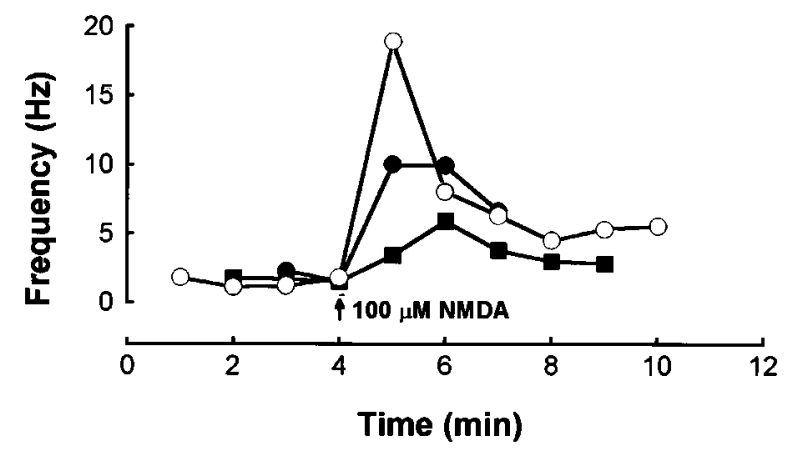

Figure 2. Potentiation of spontaneous nerve terminal currents by NMDA. $a$, Continuous trace depicts the membrane currents recorded from the nerve growth cone before and after local application of NMDA. Downward deflections are spontaneous NTCs $\left(\mathrm{V}_{\mathrm{h}}=-60 \mathrm{mV}\right.$, filtered at $150 \mathrm{~Hz}$ ). Local application of NMDA to the growth cone increased the frequency of NTCs. Samples of NTCs before and after NMDA treatment are shown below at higher time resolution. The time course-response curves were shown in $b$. Each curve connects data collected from one neuron.

$\mathrm{mV}$ ) in Ringer's solution. The solution inside the recording pipette contained $150 \mathrm{~mm} \mathrm{KCl}, 1 \mathrm{~mm} \mathrm{NaCl}, 1 \mathrm{~mm} \mathrm{MgCl}_{2}$, and $10 \mathrm{~mm}$ HEPES, $\mathrm{pH}$ 7.2. Evoked synaptic currents (ESCs) were elicited by stimulating presynaptic neurons at the soma with a heat-polished glass microelectrode (2-3 $\mu \mathrm{m}$ tip opening). The pipette was filled with Ringer's solution. For suprathreshold stimulation of the neuron, a square current pulse of $0.1 \mathrm{msec}$ duration and $0.2-2 \mu \mathrm{A}$ amplitude was applied through the pipette. Such currents generally induced twitch contraction of the muscle cell when applied to the soma of the innervating neuron. For iontophoretic mapping of ACh sensitivity, conventional micropipettes were made and filled with $3 \mathrm{~m} \mathrm{ACh}$. The resistance of the ACh pipette was $100-200 \mathrm{M} \Omega$ and required 2-6 nA of braking current. Mean amplitude of the membrane currents induced by identical pulses of ACh $(2 \mathrm{msec}$ duration) applied at the myocyte surface was used to assay ACh sensitivity. The mean SSC amplitude of manipulated synapses was obtained from 50-300 SSC events per neuron. The results were expressed as mean $\pm \mathrm{SE}(n)$ ( $n$, cell number). The statistical significance was evaluated by Student's $t$ test.

Cell manipulation experiment. In these cultures, motoneurons either form a natural synapse resulting from a random encounter of muscle cells by growing neurites or stay alone (myocyte-free, "naive neuron"). Isolated spherical myocytes (myoballs) were used in the experiment of manipulated contacts (Chow and Poo, 1985). Myoballs were first loosened from the attachment to the glass substratum by "rolling" the cell across the substratum surface with a heat-polished tight-seal micropipette. The loosening of attachment allowed the myocyte to be lifted up from the substratum and then translocated to contact with the growth cone to form a manipulated synapse. The SSC recordings were made as soon as the manipulated cells contacted with "naive" nerve terminals, and evoked stimulation at the soma was elicited a few minutes later. 
$\boldsymbol{a}$

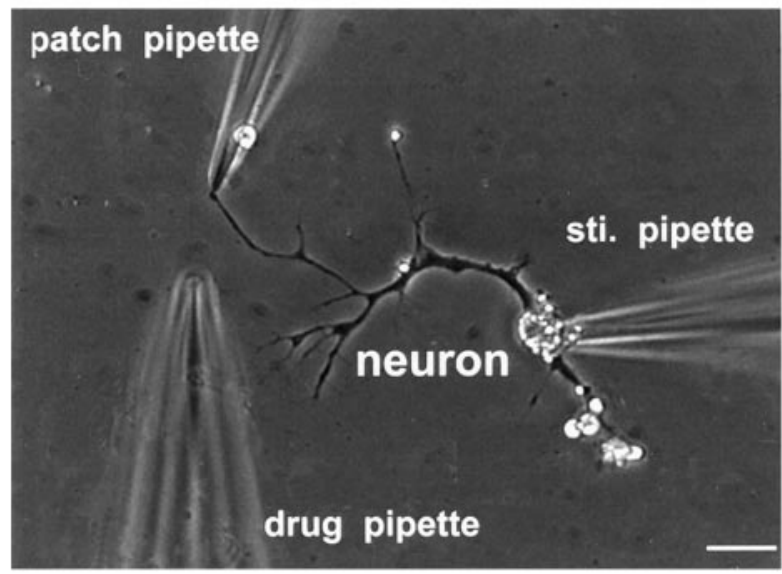

b

Figure 3. Nerve terminal potentials caused by the evoked release of ACh via the activation of nicotinic autoreceptors. $a$, Phase-contrast micrograph shows the cultured spinal neuron and the arrangement of the pipettes for whole-cell recording, electrical stimulation (sti. pipette), and drug application, respectively. Scale bar, $20 \mu \mathrm{m}$. $b$, The trace represents the change in membrane potential of nerve growth cone induced by stimulating the soma at $0.1 \mathrm{~Hz}$. The nerve growth cone was whole-cell current-clamped at resting membrane potential. Note that local perfusion with d-TC inhibited the potential change. The three to five superimposed potential signals were shown below at higher time resolution.

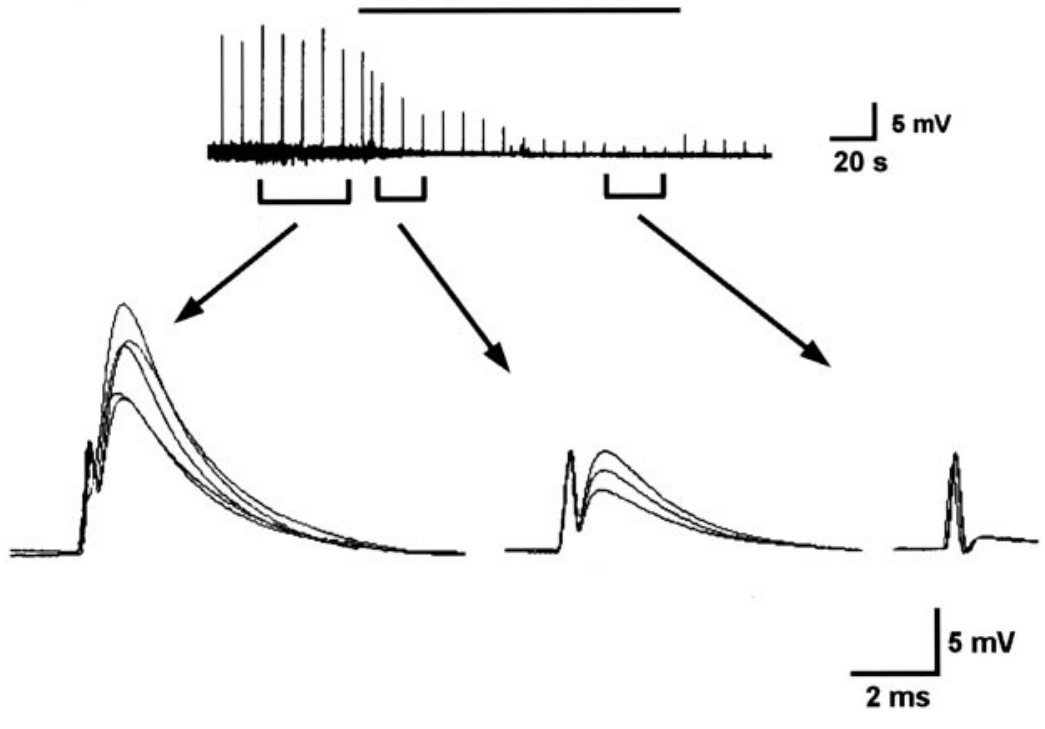

\section{RESULTS}

\section{Nerve terminal currents induced by autoreception of spontaneous $\mathrm{ACh}$ release}

Experiments were performed in 1-d-old Xenopus nerve-muscle cocultures. In these cultures, some of the motoneurons readily formed functional synapses with myocytes after a random encounter of the myocyte by the growing neurites. The axons of some of these neurons continued growing forward (Fig. 1, bottom right corner), and these neurons were chosen to do the following experiments. Whole-cell voltage-clamp recording was made on the free growth cones of these myocyte-contact neurons. We observed inward pulsatile spontaneous NTCs that resemble SSCs recorded from the postsynaptic myocyte (Fig. 1a). As shown below, these NTCs appear to be induced by quantal secretion of $\mathrm{ACh}$ from the nerve terminal and the subsequent activation of the surface nAChRs of the same nerve terminal. The average NTC frequency was $0.5 \pm 0.1 \mathrm{~Hz}(n=11)$, and the mean amplitude of NTCs was $16.9 \pm 7.3 \mathrm{pA}$, which is much smaller than that of SSCs in these 1-d-old cultures $(96.5 \pm 5.3 \mathrm{pA} ; n=22)$. When the same recording was made from naive neurons that had not made any contact with the cocultured myocytes, NTCs appeared only in 2 of 15 cases (at a frequency of 0.3 and $0.05 \mathrm{~Hz}$, respectively), suggesting the inductive role of myocytes in the spontaneous neurotransmitter secretory properties of these spinal neurons. All experiments about spontaneous NTCs described below were thus performed on myocyte-contact neurons.

nAChRs are found in a variety of vertebrate peripheral nervous system and CNS. These receptors can be divided into two distinct classes based on $\alpha$-BuTx sensitivity. The majority of $\alpha$-BuTx-sensitive nAChRs containing $\alpha 7$ and/or $\alpha 8$ subunits (Schoepfer et al., 1990; Sargent, 1993) have a relatively high permeability to $\mathrm{Ca}^{2+}$ and exert profound desensitization (Vijayaraghavan et al., 1992; McGehee et al., 1995). As shown in Figure $1 a$, local application of nicotine with another glass micropipette $(1 \mu \mathrm{m}$ pipette opening, intrapipette concentration at $10 \mu \mathrm{M})$ induced an inward current in the nerve terminal and a reduction of NTC frequency, which probably resulted from the desensitization of nAChRs. Application of $40 \mu \mathrm{M}$ d-TC inhibited the frequency of NTCs, which further characterizes the presynaptic nicotinic receptor (Fig. 1b). Pretreatment of the culture with $40 \mu \mathrm{M} \mathrm{d}$-TC (Fig. 1c) or $0.1 \mu \mathrm{M} \alpha$-BuTx (Fig. 1d) prevented the appearance of spontaneous NTCs and completely antagonized the nicotine-induced currents, suggesting that most of presynaptic nicotinic receptors at developing motoneurons belong to an 

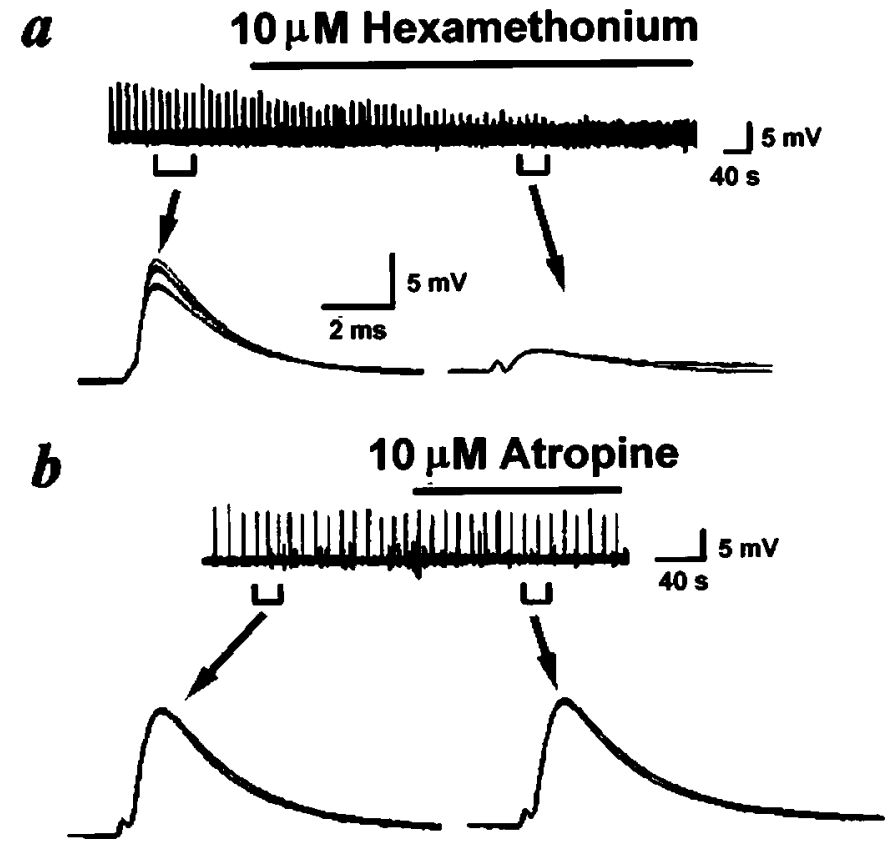

\section{c $5 \mathrm{mM} \mathrm{Mg}{ }^{2+}+0.6 \mathrm{mM} \mathrm{Ca}^{2+}$}

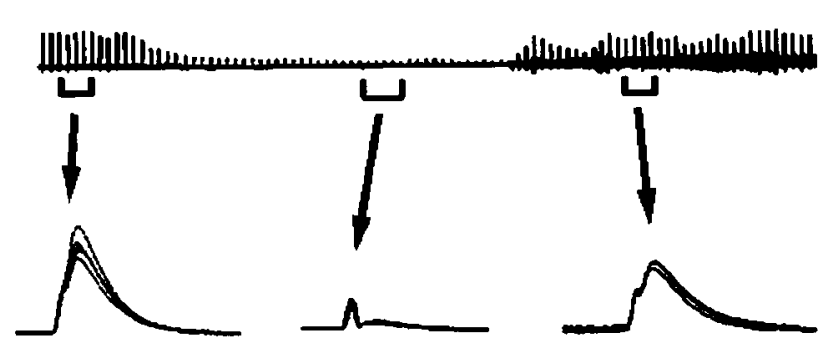

Figure 4. Inhibition of evoked ACh-induced nerve terminal potential by hexamethonium and low $\mathrm{Ca}^{2+}$ medium. Nerve growth cone was wholecell current-clamped at resting membrane potential. Evoked AChinduced nerve terminal potentials were elicited by stimulating soma at 0.1 Hz. Note that hexamethonium $(a)$, but not atropine $(b)$, inhibited these depolarizing potentials. $c$, Replacement of normal Ringer's solution with high- $\mathrm{Mg}^{2+}$, low-Ca ${ }^{2+}$ Ringer's solution reversibly inhibited the evoked ACh-induced nerve terminal potentials.

$\alpha$-BuTx-sensitive subtype. Recently, we found that glutamate markedly increased the frequency of SSCs at embryonic neuromuscular synapses via the activation of presynaptic NMDA and non-NMDA receptors (Fu et al., 1995). SSC frequency increased markedly in response to the local perfusion of glutamate at the synaptic regions, whereas only a slight increase was observed when perfusion was performed at the soma. Because an NMDA receptor is highly permeable to $\mathrm{Ca}^{2+}$ (Ascher and Johnson, 1989), we further examined the potentiating action of NMDA on ACh release. Local application of NMDA to the growth cone with another micropipette (intrapipette concentration at $100 \mu \mathrm{M}$ ) also induced an inward current (Fig. 2a), indicating the presence of an NMDA receptor in the nerve terminals. The spontaneous NTC frequency increased by more than 20 -fold after treatment with NMDA $(11.2 \pm 3.8 \mathrm{~Hz} ; n=3)$ (Fig. $2 a)$, presumably as a result of $\mathrm{Ca}^{2+}$ influx through NMDA channels. The time courseresponse curves were shown in Figure $2 b$. Pretreatment with nicotinic antagonists d-TC $(40 \mu \mathrm{M})$ or hexamethonium $(10 \mu \mathrm{M})$ significantly antagonized the NTC-increasing action of NMDA.
The addition of $5 \mathrm{~mm} \mathrm{Mg}^{2+}$ in Ringer's solution also completely inhibited the action of NMDA. These results suggest that NMDA increases $\left[\mathrm{Ca}^{2+}\right]_{\mathrm{i}}$ to enhance spontaneous quantal release of $\mathrm{ACh}$ from nerve terminals, and the released ACh then acts on the presynaptic nicotinic autoreceptors of the same nerve terminal in a feedback manner.

\section{Nerve terminal potential change induced by the autoreception of evoked $\mathrm{ACh}$ release}

As mentioned above, spontaneous NTCs are caused by the feedback action on $\alpha$-BuTx-sensitive nicotinic autoreceptors by the spontaneous quantal ACh release from nerve terminals. We further examined the nicotinic autoreception by the simultaneous secretion of multiple ACh quanta evoked by electrical stimulation at the soma. As shown in Figure $3 a$, ACh release was elicited by stimulating a naive neuron (a neuron without contact with a myocyte) at the soma with a heat-polished glass microelectrode. The pipette was filled with Ringer's solution. A square current pulse of $0.1 \mathrm{msec}$ duration and $3-5 \mathrm{~V}(0.1 \mathrm{~Hz})$ was applied through the pipette. The patch pipette was whole-cell currentclamped on the growth cone. Evoked release of ACh induced a positive potential change at nerve growth cone, which was inhibited by the local application of d-TC $(40 \mu \mathrm{M} ; n=3)$ with the third micropipette, indicating that the synchronized release of $\mathrm{ACh}$ in response to electrical stimulation also acts on the presynaptic nicotinic autoreceptors (Fig. 3b). To further characterize the evoked ACh-induced potential in the nerve terminals, the effects of other nicotinic and muscarinic antagonists were examined. Application of hexamethonium $(10 \mu \mathrm{M} ; n=3)$ (Fig. $4 a)$, but not atropine $(10 \mu \mathrm{M})$ (Fig. 4b), inhibited the evoked ACh-induced potentials. Reversible inhibition of evoked ACh-induced potentials by high $\mathrm{Mg}^{2+}$, low $\mathrm{Ca}^{2+}$ Ringer's solution $\left(5 \mathrm{mM} \mathrm{Mg}^{2+}\right.$ and $0.6 \mathrm{mM} \mathrm{Ca}^{2+}$ ) further strengthens the notion that these potentials are caused by a neurotransmitter, which is released in a $\mathrm{Ca}^{2+}$. dependent manner $(n=3)$ (Fig. $4 c)$.

\section{Regulation of synaptic transmission by the activation of presynaptic nicotinic autoreceptor}

What is the regulatory role of these presynaptic ionotropic autoreceptors in the synaptic transmission at developing motoneurons? The natural synapses of Xenopus nerve-muscle cocultures were chosen for the following experiments. SSCs were recorded from the innervated myocyte by using the whole-cell voltageclamp method. The frequency of SSCs was found to vary greatly from cell to cell, over two orders of magnitude. Whether the activation of a presynaptic nicotinic receptor is involved in the induction of high-synaptic activity was tested by examining the effect of nicotinic receptor antagonist on the SSC frequency at high-activity synapses $(\geq 3 \mathrm{~Hz})$. It was found that hexamethonium $(10 \mu \mathrm{M})$ markedly reduced the frequency of SSCs at these highactivity synapses (Fig. $5 a$ ). The SSC frequency was reduced from $6.8 \pm 0.9$ to $1.7 \pm 0.3 \mathrm{~Hz}(n=7)$. On the other hand, the SSC frequency of low-activity synapses was only slightly reduced, probably because of the inhibition of postsynaptic nicotinic receptors by hexamethonium (Fig. $5 b$ ). To further demonstrate the role of presynaptic nicotinic receptors in the regulation of evoked ACh release, ESCs were elicited by stimulating presynaptic neurons at the soma. The ESC amplitude was inhibited by $34 \%$ after application of $10 \mu \mathrm{M}$ hexamethonium $(7.7 \pm 1.2$ and $5.1 \pm 0.7 \mathrm{nA}$, before and after treatment with hexamethonium, respectively; $n=6$ ) (Fig. 5c). Because the iontophoretic ACh-induced currents were inhibited by only $11 \%$ after treatment with hexamethonium 

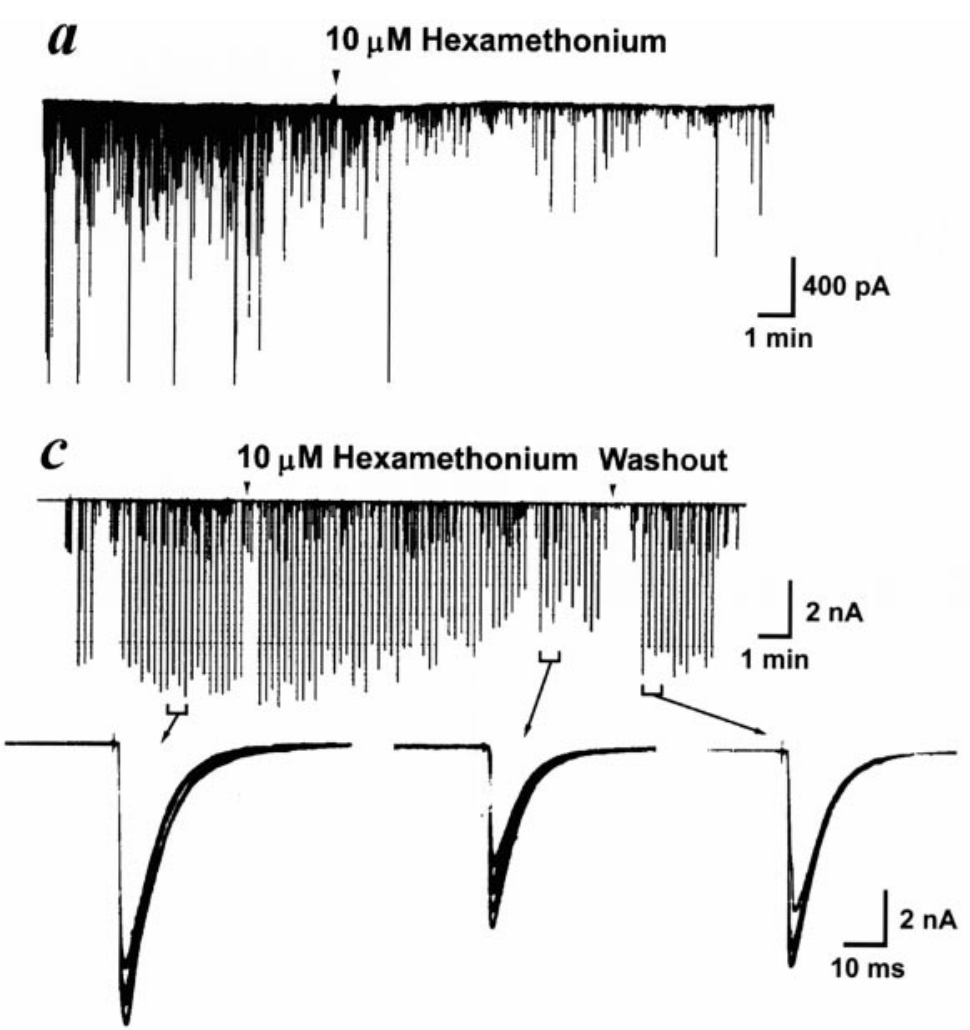
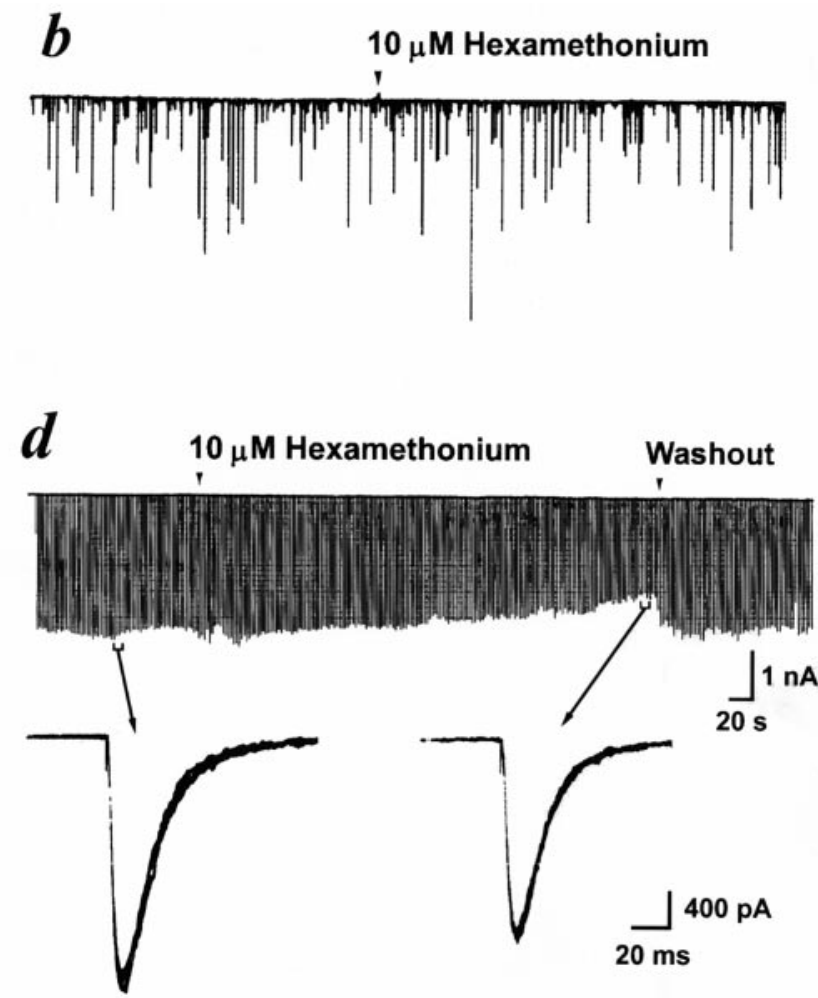

Figure 5. Positive feedback regulation of ACh release by the activation of presynaptic nicotinic autoreceptors. The innervated myocyte was whole-cell voltage-clamped at $-60 \mathrm{mV}$. Downward deflections indicated SSCs (filtered at $150 \mathrm{~Hz}$ ). Application of nicotinic receptor antagonist hexamethonium markedly inhibited the spontaneous ACh release of the high-activity synapses $(a)$ but only slightly affected that of low-activity synapses $(b)$. $c$, A presynaptic neuron was stimulated at the soma to induce ESCs at $0.1 \mathrm{~Hz}$. Note that application of hexamethonium inhibited the ESCs by $34 \%$. $d$, Identical iontophoretic pulses of ACh at $0.5 \mathrm{~Hz}$ were applied to the surface of an isolated myocyte. Application of hexamethonium only slightly inhibited the iontophoretic ACh-induced currents.

$(1.8 \pm 0.3$ and $1.6 \pm 0.2 \mathrm{nA}$, before and after treatment with hexamethonium, respectively; $n=4$ ) (Fig. $5 d$ ), the higher degree of inhibition of ESCs may result from the presynaptic nicotinic inhibition of hexamethonium. Therefore, the activation of presynaptic nicotinic receptors may have positive regulation of evoked ACh release. To further exclude the possible postsynaptic inhibition by nicotinic antagonists, we examined the ESCs by moving a myoball (M1) to form a manipulated synapse with a naive neuron (Fig. $6 a$ ). After obtaining the control evoked responses (Fig. $6 b$, left side, middle trace), the culture was treated with $\alpha$-BuTx (60 nM) for $20 \mathrm{~min}$, which irreversibly inhibited the presynaptic nicotinic receptors, and then was washed three times with plain Ringer's solution. The second myoball (M2) from another culture dish, which was not treated with $\alpha$-BuTx, was manipulated to form a synapse at the same site, and the evoked responses were measured again (Fig. 6b, right side, middle trace). As shown in Figure $6 b$, bottom panels, the ESC amplitude was inhibited by $39 \%$ after $\alpha$-BuTx treatment (from $1.6 \pm 0.2$ to $0.9 \pm$ $0.2 \mathrm{nA} ; n=8 ; p<0.05)$. Because the SSC amplitude of two myoballs before and after $\alpha$-BuTx treatment did not show a significant difference $(\mathrm{M} 1,188.8 \pm 32.7 \mathrm{pA} ; \mathrm{M} 2,165.2 \pm 24.0 \mathrm{pA}$, respectively; $n=6 ; p>0.05$ ) (Fig. $6 b$, top panels) excludes the possible residual postsynaptic inhibitory effect of $\alpha$-BuTx. For comparison, two myoballs (M1 and M2) were manipulated to contact with the same site of the control neuron, which was not treated with $\alpha$-BuTx, in an interval of $30 \mathrm{~min}$, and the evoked responses were measured in M1 and M2, respectively. The ESC amplitude between two manipulated myoballs shows no signifi- cant difference in this case $(\mathrm{M} 1,1.4 \pm 0.1 \mathrm{nA} ; \mathrm{M} 2,1.80 \pm 0.5 \mathrm{nA}$, respectively; $n=4 ; p>0.05)$. In addition, after treatment of the neuron with $\alpha$-BuTx and washout, the ESC amplitude was slightly inhibited by $19.7 \pm 7.0 \%(n=4)$ in response to the application of $10 \mu \mathrm{M}$ hexamethonium, which primarily resulted from its postsynaptic inhibition. This result indicates the marked reduction of presynaptic inhibition by hexamethonium in the $\alpha$-BuTx-treated nerve terminal.

\section{DISCUSSION}

The major findings reported here are that the activation of $\alpha$-BuTX-sensitive nicotinic autoreceptors by spontaneously released ACh can induce NTCs in the same neuron. The appearance of NTCs is very much like that of SSCs, which are recorded in postsynaptic cells. Increase of intracellular $\mathrm{Ca}^{2+}$ by NMDA application enhanced the frequency of NTCs. The NTCs were blocked by hexamethonium, d-TC, and $\alpha$-BuTx, suggesting that the AChRs present on the nerve terminals are predominantly the nicotinic type. The neuronal $\mathrm{nAChRs}$ are involved in cholinergic transmission in the peripheral nervous system, as well as in the CNS (Bertrand and Changeux, 1995; Role and Berg, 1996). To date, 11 members of the nAChR family have been identified and cloned from vertebrate genomes (Lindstrom, 1996). One of the most prominent classes of nAChRs contains the $\alpha 7$ and/or $\alpha 8$ gene product. Such receptors have a relatively high permeability to $\mathrm{Ca}^{2+}$ and bind $\alpha$-BuTx with high affinity (Couturier et al., 1990; Schoepfer et al., 1990; Vijayaraghavan et al., 1992; Seguela et al., 1993). This type of nAChR is fully blocked by low con- 


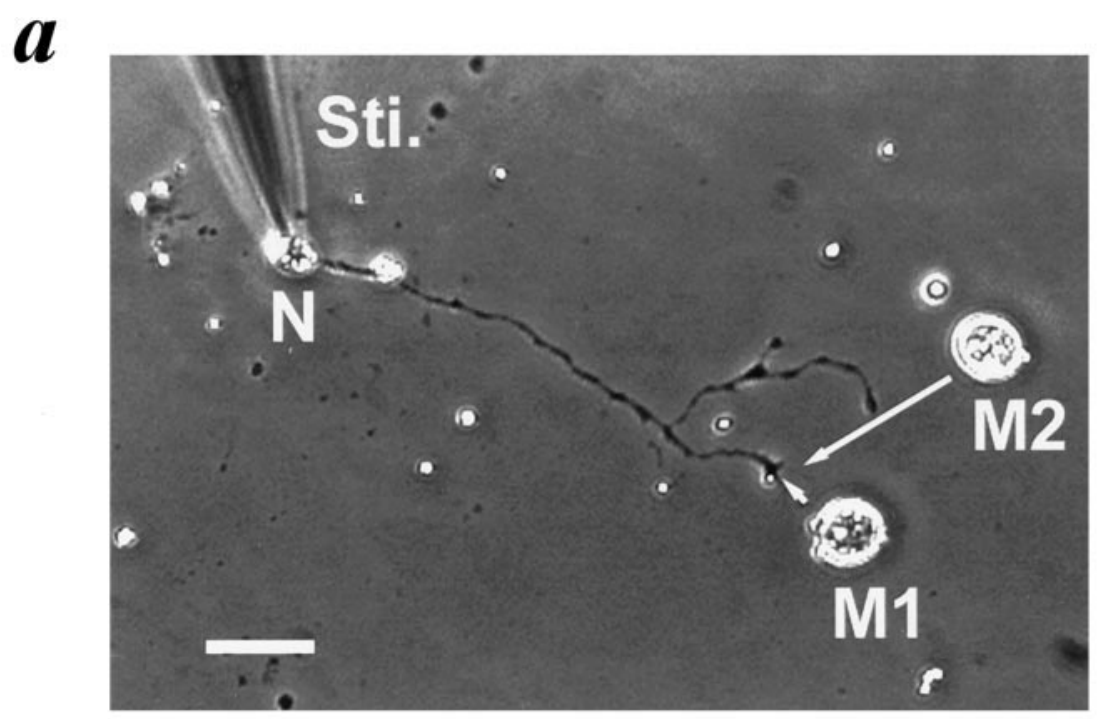

b

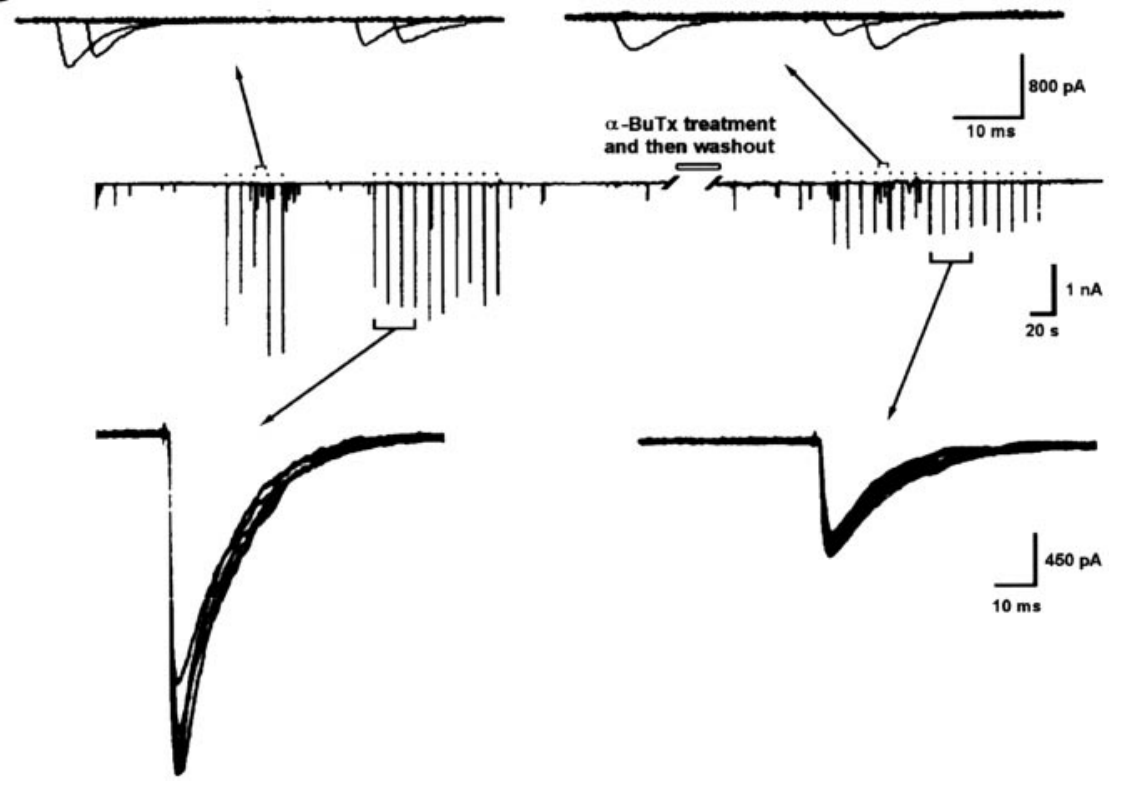

Figure 6. Pretreatment of neurons with $\alpha$-bungarotoxin inhibited evoked synaptic currents in manipulated synapses. $a$, The photograph shows that the ESCs were examined by moving a myoball (M1) to form a manipulated synapse with a naive neuron $(N)$. After obtaining the control ESCs by stimulating (Sti.) the soma at $0.1 \mathrm{~Hz}$, the M1 was removed away, and the culture was treated with $\alpha$-BuTx (60 nM) for $20 \mathrm{~min}$ and then washed three times with plain Ringer's solution. The second myoball (M2) from another culture dish, which was not treated with toxin, was then manipulated to form a synapse at the same site, and the evoked responses were measured again. Scale bar, $30 \mu \mathrm{m}$. $b$, The downward deflections in the middle trace indicated SSCs and ESCs (filled circles) (filtered at $150 \mathrm{~Hz}$ ) $\alpha$-BuTx treatment significantly inhibited the amplitude of ESCs but not that of SSCs. The top panels show the representative superimposed SSC events during a $10 \mathrm{sec}$ period, and the bottom panels show the four superimposed ESCs at higher time resolution. centrations of $\alpha$-BuTx, and the blockade is relatively irreversible, as is true of $\alpha$-BuTx binding to skeletal muscle AChRs (Smith et al., 1985). The conclusion that $\alpha$-BuTx-sensitive nAChRs are responsible for the positive regulation of $\mathrm{ACh}$ release is supported by the pharmacological evidence showing that block of presynaptic AChRs by $\alpha$-BuTx can inhibit evoked ACh release or the SSC frequency at high-activity synapses. Treatment of neurons with $\alpha$-BuTx and then washout resulted in the inhibition of evoked synaptic currents of the second manipulated myoball. This result arises from the blockade of $\alpha$-BuTx-sensitive receptors on the presynaptic nerve terminals rather than from postsynaptic receptors, because $\alpha$-BuTx blocked 39\% of the synaptic responses evoked by nerve stimulation but had little effect on the mean amplitude of SSCs between two manipulated myoballs. The positive feedback regulation of ACh release by the activation of an $\alpha$-BuTx-sensitive nicotinic autoreceptor may result from the $\mathrm{Ca}^{2+}$ influx directly through the AChR channel. However, voltage-gated $\mathrm{Ca}^{2+}$ channels represent a second pathway by which extracellular $\mathrm{Ca}^{2+}$ could enter the cell. In the cultured
Xenopus motoneuron, $\mathrm{N}$-type $\mathrm{Ca}^{2+}$ channels are responsible for action potential-evoked $\mathrm{ACh}$ release, because $\omega$-conotoxin completely inhibited the evoked synaptic currents (data not shown). On the other hand, L-type $\mathrm{Ca}^{2+}$ channels are involved in the regulation of spontaneous $\mathrm{ACh}$ release at high-activity synapses (Fu and Huang, 1994). It was demonstrated here that the activation of presynaptic $\alpha$-BuTx-sensitive nicotinic autoreceptors by spontaneously released ACh is able to produce substantial membrane depolarization, which may thus open voltage-gated $\mathrm{Ca}^{2+}$ channels and thereby augment $\mathrm{Ca}^{2+}$ entry. In addition, it was found that the evoked release of $\mathrm{ACh}$ is also able to induce substantial membrane depolarization. In view of the dependence of this evoked response on extracellular $\mathrm{Ca}^{2+}$, the evokedinduced potential change in nerve terminal may result from $\mathrm{Ca}^{2+}$-dependent $\mathrm{ACh}$ release, which is also inhibited by nicotinic antagonists d-TC and hexamethonium but not by the muscarinic antagonist atropine. At high-activity synapses, the presynaptic nicotinic autoreceptor can be tonically activated by the ambient $\mathrm{ACh}$. Here, it seems that the response of presynaptic nAChR 
after bath application of nicotine desensitized more slowly than that reported elsewhere (Couturier et al., 1990). Some nAChRs, including $\alpha 7$, may contain more than a single type of $\alpha$ or $\beta$ subunit. Such differences may result in changes in desensitization properties (Ramirez-Latorre et al., 1996; Wang et al., 1996).

The effects of the nicotinic antagonist d-TC on ACh release from adult motor nerve terminals are the subject of much controversy. It is generally accepted that d-TC possesses a prejunctional action at the neuromuscular junction. This is manifest in twitch tension experiments as tetanic fade, i.e., the inability of a muscle to sustain tension during high-frequency stimulation and in electrophysiological experiments as an enhanced diminution of the amplitude of end-plate potentials during high-frequency stimulation of motoneurons (Magleby et al., 1981; Gibb and Marshall, 1984). It is proposed that these putative receptors form part of a positive-feedback system; activation of presynaptic nicotinic autoreceptors by $\mathrm{ACh}$ enhances the mobilization and release of ACh during high-frequency stimulation of motoneurons. In the current study, the presynaptic nAChRs are sensitive to the inhibition by $\alpha$-BuTx, and thus, most nAChRs are highly $\mathrm{Ca}^{2+}$ permeable. Here, we found that the activation of presynaptic nicotinic receptors at developing motoneurons has positive regulation in both spontaneous and evoked ACh release. However, there is no tetanic fade phenomenon in these embryonic motoneurons (Fu and Liu, 1997).

The $\alpha$-BuTx-sensitive nAChR would have the potential of influencing a vast array of $\mathrm{Ca}^{2+}$-related events in the neurons because of its high permeability to $\mathrm{Ca}^{2+}$. In addition to regulating transmitter release, as is the case in chick retinal cells and the pheochromocytoma cell line PC12, cholinergic antagonists or $\alpha$-BuTx has been shown to promote the extension of neurites (Lipton et al., 1988; Quik et al., 1990). Because both types of cultures can synthesize and release ACh under some conditions (Greene and Rein, 1977; Lipton, 1988), the $\alpha$-BuTx effects may result from its inhibition of nicotinic autoreceptor activation. In the chick ciliary ganglion, the $\alpha$-BuTx-sensitive nAChRs have been shown to have a predominantly nonsynaptic location on neurons and may be concentrated on pseudodendrites emerging from the soma (Jacob and Berg, 1983). Activation of this type of nAChRs on ciliary ganglion neurons in dissociated cell culture inhibits neurite extension and induces a partial retraction of the processes in a $\mathrm{Ca}^{2+}$-dependent manner (Pugh and Berg, 1994). The $\alpha$-BuTx effects can thus be interpreted as relieving an ongoing ACh-induced inhibition of neurite outgrowth. From a preliminary study, we found that bath application of $\alpha$-BuTx to $4 \mathrm{hr}$ cultured Xenopus spinal neurons also enhanced axonal growing rate, indicating that activation of a nicotinic autoreceptor inhibits the axonal growth (our unpublished observations). The nAChRs of growth cone may play a role in neurite arrest after target contact. We found here that the growth cone of myocyte-contact neuron exhibits more NTCs than that of naive neurons. In addition, myocytes are also able to secrete ACh (Fu et al., 1998). Presynaptic $\alpha$-BuTx-sensitive nAChRs could thus provide a mechanism for terminating axonal growth when the axon contacts with myocyte. Therefore, nicotinic autoreceptor in the growth cone may play functional roles in nerve growth, plasticity of neurites, and synapse formation (Chan and Quik, 1993).

In conclusion, our results provide to our knowledge the first electrophysiological evidence that ionotropic autoreceptors can be activated by the endogenously released neurotransmitter. We showed here that the $\alpha$-BuTx-sensitive nAChRs in presynaptic nerve terminals are ligand-gated ion channels and are cation selective. The membrane potential change via the activation of nicotinic autoreceptors by endogenously released ACh provides a possible mechanism for both endogenous and exogenous cholinergic agents in the CNS. Activation of autoreceptors by endogenously released ACh will further increase the efficacy of cholinergic neurons. Presynaptic nicotinic autoreceptors may play an important role in the regulation of synaptic transmission, neuronal growth, and synaptogenesis.

\section{REFERENCES}

Araujo DM, Lapchak PA, Collier B, Quirion R (1988) Characterization of $N-\left[{ }^{3} \mathrm{H}\right]$ methylcarbamylcholine binding sites and effect of $\mathrm{N}$-methylcarbamylcholine on acetylcholine release in rat brain. J Neurochem 51:292-299.

Arneric SP, Sullivan JP, Williams M (1995) Neuronal nicotinic acetylcholine receptors. Novel targets for central nervous system therapeutics. In: Psychopharmacology: the fourth generation of progress (Bloom FE, Kupfer DJ, eds), pp 95-110. New York: Raven.

Ascher P, Johnson JW (1989) The NMDA receptor, its channel and its modulation by glycine. In: The NMDA receptor (Watkins JC, Collingridge GL, eds), pp 109-121. Oxford: Oxford UP.

Bertrand D, Changeux JP (1995) Nicotinic receptor: an allosteric protein specialized for intercellular communication. Semin Neurosci 7:75-90.

Boehm S, Huck S (1996) Inhibition of N-type calcium channels: the only mechanism by which presynaptic $\alpha 2$-autoreceptors control sympathetic transmitter release. Eur J Neurosci 8:1924-1931.

Bowmann WC, Marshall IG, Gibb AJ, Harborne AJ (1988) Feedback control of transmitter release at the neuromuscular junction. Trends Pharmacol Sci 9:16-20.

Chan J, Quik M (1993) A role for the nicotinic $\alpha$-bungarotoxin receptor in neurite outgrowth in PC12 cells. Neuroscience 56:441-451.

Chow I, Poo MM (1985) Release of acetylcholine from embryonic neuron upon contact with muscle cell. J Neurosci 5:1076-1082.

Clarke PBS (1993) Nicotinic receptors in mammalian brain: localization and relation to cholinergic innervation. Prog Brain Res 98:77-82.

Coggan JS, Paysan J, Conroy WG, Berg DK (1997) Direct recording of nicotinic responses in presynaptic nerve terminals. J Neurosci 17:5798-5806.

Couturier S, Bertrand D, Matler J-M, Hernandez M-C, Bertrand S, Miller N, Valera S, Barkas T, Ballivet M (1990) A neuronal nicotinic acetylcholine receptor subunit $(\alpha 7)$ is developmentally regulated and forms a homo-oligomeric channel blocked by $\alpha$-BTX. Neuron 5:847-856.

Cragg SJ, Greenfield SA (1997) Differential autoreceptor control of somatodendritic and axon terminal dopamine release in substantia nigra, ventral tegmental area, and striatum. J Neurosci 17:5738-5746.

Fu WM, Huang FL (1994) L-type $\mathrm{Ca}^{2+}$ channel is involved in the regulation of spontaneous transmitter release at developing neuromuscular synapses. Neuroscience 58:131-140.

Fu WM, Liu JJ (1997) Regulation of acetylcholine release by presynaptic nicotinic receptors at developing neuromuscular synapses. Mol Pharmacol 51:390-398.

Fu WM, Liou JC, Lee YH, Liou HC (1995) Potentiation of neurotransmitter release by activation of presynaptic glutamate receptors at developing neuromuscular synapses of Xenopus. J Physiol (Lond) 489:813-823.

Fu W M, Liou HC, Chen YH, Wang SM (1998) Release of acetylcholine from embryonic myocyte in Xenopus cell cultures. J Physiol (Lond) 509:497-506.

Gibb AJ, Marshall IG (1984) Pre- and post-junctional effects of tubocurarine and other nicotinic antagonists during repetitive stimulation in the rat. J Physiol (Lond) 351:275-297.

Gothert M, Fink K, Frolich D, Likungu J, Molderings G, Schlicker E, Zentner J (1996) Presynaptic 5-HT auto- and heteroreceptors in the human central and peripheral nervous system. Behav Brain Res 73:89-92.

Gray R, Rajan AS, Radcliffe KA, Yakehiro M, Dani JA (1996) Hippocampal synaptic transmission enhanced by low concentrations of nicotine. Nature 383:713-716.

Greene LA, Rein G (1977) Synthesis, storage and release of acetylcholine by a noradrenergic pheochromocytoma cell line. Nature 268:349-351.

Guo JZ, Tredway TL, Chiappinelli VA (1998) Glutamate and GABA 
release are enhanced by different subtypes of presynaptic receptors in the lateral geniculate nucleus. J Neurosci 18:1963-1969.

Hamill OP, Marty A, Neher E, Sakmann B, Sigworth FJ (1981) Improved patch-clamp techniques for high-resolution current recording from cells and cell-free membrane patches. Pflügers Arch 391:85-100.

Jacob MH, Berg DK (1983) The ultrastructural localization of $\alpha$-bungarotoxin binding sites in relation to synapses on chick ciliary ganglion neurons. J Neurosci 3:260-271.

Levin ED (1992) Nicotinic systems and cognitive function. Psychopharmacology 108:417-431.

Li X, Rainnie DG, McCarley RW, Green RW (1998) Presynaptic nicotinic receptors facilitate monoaminergic transmission. J Neurosci 18:1904-1912.

Lindstrom J (1996) Neuronal nicotinic acetylcholine receptors. Ion Channels 4:377-450.

Lipton SA (1988) Spontaneous release of acetylcholine affects the physiological nicotinic responses of rat retinal ganglion cells in culture. J Neurosci 8:3857-3868.

Lipton SA, Frosch MP, Phillips MD, Tauck DL, Aizenman E (1988) Nicotinic antagonists enhance process outgrowth by rat retinal ganglion cells in culture. Science 239:1293-1296.

Macek TA, Winder DG, Gereau RW, Ladd CO, Conn PJ (1996) Differential involvement of group II and group III mGluRs as autoreceptors at lateral and medial perforant path synapses. J Neurophysiol 76:3798-3806.

Magleby KL, Pallotta BS, Terrar DA (1981) The effect of (+)tubocurarine on neuromuscular transmission during repetitive stimulation in the rat, mouse, and frog. J Physiol (Lond) 312:97-113.

McGehee DS, Role LW (1995) Physiological diversity of nicotinic acetylcholine receptors expressed by vertebrate neurons. Annu Rev Physiol 57:521-546.

McGehee D, Heath M, Gelber S, Role LW (1995) Nicotinic enhancement of fast excitatory synaptic transmission in CNS by presynaptic receptors. Science 269:1692-1697.

Misgeld U, Bijak M, Jarolimek W (1995) A physiological role for $\mathrm{GABA}_{\mathrm{B}}$ receptors and the effects of baclofen in the mammalian central nervous system. Prog Neurobiol 46:423-462.

Nieuwkoop PD, Faber J (1967) Normal table of Xenopus laevis, Ed 2. Amsterdam: North-Holland.

Nordberg A, Nilsson-Hakansson L, Adem A, Hardy J, Alafuzoff I, Lai Z, Herrera-Marschitz M, Winblad B (1989) The role of nicotinic receptors in the pathophysiology of Alzheimer's disease. Prog Brain Res 79:353-362.

Pugh PC, Berg DK (1994) Neuronal acetylcholine receptors that bind $\alpha$-bungarotoxin mediate neurite retraction in a calcium-dependent manner. J Neurosci 14:889-896.
Quik M, Cohen R, Audhya T, Goldstein G (1990) Thymopoietin interacts at the $\alpha$-bungarotoxin site and induces process formation in PC12 pheochromocytoma cells. Neuroscience 39:139-150.

Ramirez-Latorre J, Yu CR, Qu X, Perin F, Karlin A, Role L (1996) Functional contributions of $\alpha 5$ subunit to neuronal acetylcholine receptor channels. Nature 380:347-351.

Role LW, Berg DK (1996) Nicotinic receptors in the development and modulation of CNS synapses. Neuron 16:1077-1085.

Rowell PP, Winkler DL (1984) Nicotinic stimulation of $\left[{ }^{3} \mathrm{H}\right]$ acetylcholine release from mouse cerebral cortical synaptosomes. J Neurochem 43:1593-1598.

Sargent PB (1993) The diversity of neuronal nicotinic acetylcholine receptors. Annu Rev Neurosci 16:403-443.

Schoepfer R, Conroy WG, Whiting P, Gore M, Lindstrom J (1990) Brain $\alpha$-bungarotoxin binding protein cDNAs and MABs reveal subtypes of this branch of the ligand-gated ion channel gene superfamily. Neuron 5:35-48.

Seguela P, Wadiche J, Dineley-Miller K, Dani JA, Patrick JW (1993) Molecular cloning, functional properties, and distribution of rat brain $\alpha 7$ : a nicotinic cation channel highly permeable to calcium. J Neurosci 13:596-604.

Smith MA, Stollberg J, Lindstrom JM, Berg DK (1985) Characterization of a component in chick ciliary ganglia that cross-reacts with monoclonal antibodies to muscle and electric organ acetylcholine receptor. J Neurosci 5:2726-2731.

Starke K, Gothert M, Kilbinger H (1989) Modulation of neurotransmitter release by presynaptic autoreceptors. Physiol Rev 69:864-989.

Tabti N, Poo MM (1991) Culturing spinal cord neurons and muscle cells from Xenopus embryos. In: Culturing nerve cells (Banker G, Goslin K, eds) pp 137-154. Cambridge, MA: MIT.

Vijayaraghavan S, Pugh PC, Zhang ZW, Rathouz MM, Berg DK (1992) Nicotinic receptors that bind $\alpha$-bungarotoxin on neurons raise intracellular free $\mathrm{Ca}^{2+}$. Neuron 8:353-362.

Wang F, Gerzanich V, Wells GB, Anand R, Peng X, Keyser K, Lindstrom J (1996) Assembly of human neuronal nicotinic receptor alpha 5 subunits with alpha 3 , beta 2 , and beta 4 subunits. J Biol Chem 271:17656-17665.

Wessler I (1992) Acetylcholine at motor nerves: storage, release, and presynaptic modulation by autoreceptors and adrenoceptors. Int Rev Neurobiol 34:283-384.

Wilkie GI, Hutson P, Sullivan JP, Wonnacott S (1996) Pharmacological characterization of a nicotinic autoreceptor in rat hippocampal synaptosomes. Neurochem Res 21:1141-1148.

Wonnacott S, Irons J, Rapier C, Thorne B, Lunt GG (1989) Presynaptic modulation of transmitter release by nicotinic receptors. Prog Brain Res 79:157-163. 